\title{
Variation of infrapatellar sensory innervation: a case report and review of the literature
}

\author{
Ali Fırat Esmer ${ }^{1}$, Hakan Orbay ${ }^{2}$, Nihal Apaydın', Tülin Şen', Alaittin Elhan ${ }^{1}$ \\ ${ }^{1}$ Department of Anatomy, School of Medicine, Ankara University, Ankara, Turkey \\ ${ }^{2}$ Department of Plastic and Reconstructive Surgery, Ankara Numune Training and Research Hospital, Ankara, Turkey
}

\begin{abstract}
Generally infrapatellar region is innervated by the infrapatellar branch of the saphenous nerve and the branches of medial cutaneous femoral nerve that form a plexus so called subsartorial plexus. We found that saphenous nerve after leaving the adductor canal did not give an infrapatellar branch but the whole sensory nerves of the infrapatellar region were originating from medial cutaneous femoral nerve in a cadaver. A detailed anatomic knowledge about the innervation of the infrapatellar region is mandatory for knee surgeons. Surgeons should always consider the extreme variability of infrapatellar innervation and should pay extra attention to protect the innervating nerve during dissection.
\end{abstract}

Key words: saphenous nerve; infrapatellar region; infrapatellar branch; innervation

Anatomy 2009; 3: 62-64, (c) 2009 TSACA

\section{Introduction}

Infrapatellar region is innervated by the infrapatellar branch of the saphenous nerve and the branches of medial cutaneous femoral nerve that form a plexus so called subsartorial plexus. ${ }^{1}$ The saphenous nerve is the largest and the longest branch of the femoral nerve. ${ }^{2}$ It enters the adductor canal with femoral artery and vein but leaves the canal close to its distal end coursing on the medial side of the knee joint. It provides sensory innervation to the infrapatellar region via its infrapatellar branch $^{1}$ and courses distally innervating the medial lower leg and the dorsum of the foot. ${ }^{2}$ The medial cutaneous femoral nerve courses more laterally and its branches distribute to the infrapatellar region thus contributing to the innervation of this region. ${ }^{1}$

Injury to the infrapatellar branch of saphenous nerve and the branch of medial cutaneous femoral nerve is a common complication of either arthroscopic or open knee surgery. ${ }^{3-6}$ Such an injury may lead to lower leg paresthesia or numbness, neuroma or reflex sympathetic dystrophy. ${ }^{7-14}$ A detailed anatomic knowledge about the innervation of the infrapatellar region is mandatory to avoid this discomforting complication. Although a number of papers on the variability of infrapatellar innervation have been published none of them have mentioned the absence of contribution of saphenous nerve. ${ }^{4,9,15-20}$ In the dissection of the left lower extremity of a cadaver we have noticed that saphenous nerve did not have an infrapatellar branch but the infrapatellar innervation was solely supplied by the medial cutaneous femoral nerve.

\section{Case Report}

The cadaver was a 32-year-old male embalmed in $10 \%$ formalin. The left lower extremity of the cadaver was dissected layer by layer and a variation of the infrapatellar innervation was noted. Saphenous nerve after 
leaving the adductor canal did not give an infrapatellar branch but the whole sensory nerves of the infrapatellar region were originating from medial cutaneous femoral nerve (Figure 1). No connection between the saphenous nerve and the infrapatellar branches of the medial femoral cutaneous nerve was noted on dissection.

\section{Discussion}

Iatrogenic injury of the branches of saphenous nerve and the medial femoral cutaneous nerve innervating the infrapatellar region may lead only to an insignificant numbnessbut also to painful neuroma and reflex sympathetic dystrophy decreasing the quality of life of the patients. ${ }^{1,20}$ These complications are most frequently seen in anterior cruciate ligament reconstruction (incidences up to $58 \%$ has been reported). To decrease the incidence of this complication various studies on the variations of the sensory nerves of the infrapatellar region have been carried out. ${ }^{4,915-20}$ All of these studies documented the contribution of both the saphenous and medial cutaneous femoral nerve to the innervation of infrapatellar region and attempted to define a safe zone for the medial approach to the knee joint but to our knowledge none of them mentioned about the medial cutaneous femoral nerve being the sole contributor to the infrapatellar innervation and absence of infrapatellar branch of saphenous nerve.
Tifford et al. reported that in a series of 20 cadavers they consistently found the infrapatellar branch of the saphenous nerve composed of 2 main trunks. ${ }^{20}$ Mochida and Kikuchi further reported the variations of these two main trunks. ${ }^{9}$ Mochizuki et al. reported that infrapatellar region is innervated by medial cutaneous femoral nerve proximally and saphenous nerve distally and stated that these two nerves have a complicated distribution in infrapatellar region. ${ }^{1}$ Kartus et al. reported the presence of infrapatellar nerve in a wider series including 60 lower extremities. ${ }^{4}$ Hunter et al. reported the presence of infrapatellar nerve in 20 lower extremities of 10 cadavers with slight variations in location. ${ }^{7}$ Arthornthurasook and Gaew-Im also found inferior patellar branch of the saphenous nerve in all 230 cadavers they studied and classified the nerve into 4 types according to its relationship to the sartorious muscle: posterior, penetrating, parallel, and anterior. ${ }^{15}$ Ebraheim and Mekhail detected the infrapatellar branch of saphenous nerve in all of the 28 lower extremities dissected by them and tried to define a safe zone to avoid injury to these nerves during surgical procedures. ${ }^{17}$ But complicated anatomic variations of the innervation of the infrapatellar region prevented the definition of a completely safe zone up to date. ${ }^{1}$

In conclusion, surgeons should always consider the extreme variability of infrapatellar innervation and should pay extra attention to protect the innervating nerve during dissection.

Figure 1. The infrapatellar branch originated from medial cutaneous femoral nerve. MFCN: medial cutaneous femoral nerve.

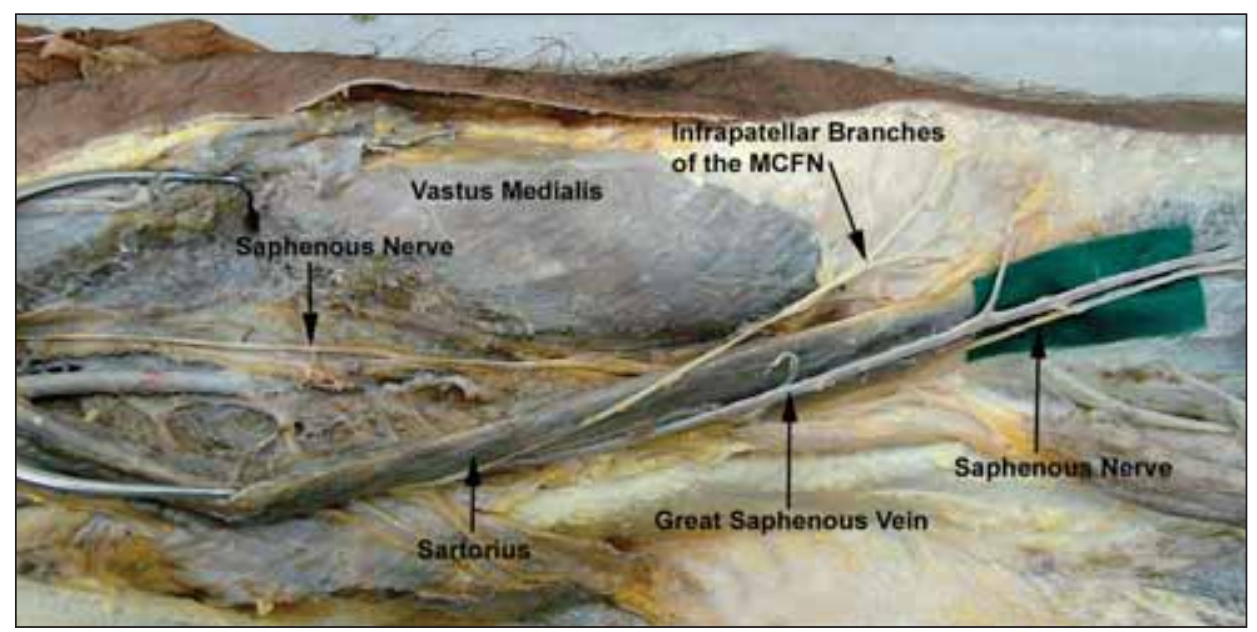




\section{References}

1. Mochizuki T, Akita K, Muneta T, et al. Anatomical bases for minimizing sensory disturbance after arthroscopically-assisted anterior cruciate ligament reconstruction using medial hamstring tendons. Surg Radiol Anat 2003; 25: 192-9.

2. Papastergiou SG, Voulgaropoulos H, Mikalef $P$, et al. Injuries to the infrapatellar branch(es) of the saphenous nerve in anterior cruciate ligament reconstruction with four-strand hamstring tendon autograft: vertical versus horizontal incision for harvest. Knee Surg Sports Traumatol Artbrosc 2005; 23: 1-5.

3. Abbott LC, Carpenter WF. Surgical approaches to the knee joint. 7 Bone foint Surg 1945; 27: 277.

4. Kartus J, Ejerhed L, Eriksson BI, et al. The localization of the infrapatellar nerves in the anterior knee region with special emphasis on central third patellar tendon harvest: a dissection study on cadaver and amputated specimens. Artbroscopy 1999; 15: 577-86.

5. Sgaglione NA, Warren RF, Wickiewicz TL, et al. Primary repair with semitendinosus tendon augmentation of acute anterior cruciate ligament injuries. Am 7 Sports Med 1990; 18: 64-73.

6. Tillett E, Madsen R, Rogers R, et al. Localization of the semitendinosus- gracilis tendon bifurcation point relative to the tibial tuberosity: An aid to hamstring tendon harvest. Artbroscopy 2004; 20: $51-4$

7. Hunter LY, Louis DS, Ricciardi Jr, et al. The saphenous nerve its course and importance in medial arthrotomy. Am 7 Sports Med 1979; 7: 227-30.

8. Mintzer CM, Richmond JC, Taylor J. Meniscal repair in the young athlete. Am 7 Sports Med 1998; 26: 630-3.

9. Mochida H, Kikuchi S. Injury to infrapatellar branch of saphenous nerve in arthroscopic knee surgery. Clin Orthop 1995; 320: 88-9.
10. Pınar H, Özkan M, Akseki D, et al. Traumatic prepatellar neuroma: an unusual cause of anterior knee pain. Knee Surg Sports Traumatol Arthrosc 1996; 4: 154-6.

11. Poehling GG, Pollock FE Jr, Koman LA. Reflex sympathetic dystrophy of the knee after sensory nerve injury. Arthroscopy 1988; 4: 31-5.

12. Swanson AJG. The incidence of prepatellar neuropathy following medial meniscectomy. Clin Orthop 1983; 181: 151-3.

13. Tennent TD, Birch NC, Holmes MJ, et al. Knee pain and the infrapatellar branch of the saphenous nerve. 7 R Soc Med 1998; 91 : 573-5.

14. Boon JM, Van Wyk MJ, Jordaan D. A safe area and angle for harvesting autogenous tendons for anterior cruciate ligament reconstruction. Surg Radiol Anat 2004; 26: 167-71.

15. Arthornthurasook A, Gaew-Im K. Study of the infrapatellar nerve. Am 7 Sports Med 1988; 16: 57-9.

16. Arthornthurasook A, Gaew-Im K. The sartorial nerve: Its relationship to the medial aspect of the knee. Am 7 Sports Med 1990; 18: 41-2.

17. Ebraheim NA, Mekhail AO. The infrapatellar branch of the saphenous nerve: an anatomic study. 7 Orthop Trauma 1997; 11: 195-9.

18. Ganzoni N, Wieland K. The ramus infrapatellaris of the saphenous nerve and its importance for medial parapatellar arthrotomies of the knee. Reconstr Surg Traumatol 1978; 16: 95-100.

19. Horner G, Dellon L. Innervation of the human knee joint and implications for surgery. Clin Orthop 1994; 301: 221-6.

20. Tifford CD, Spero L, Luke T, et al. The relationship of the infrapatellar branches of the saphenous nerve to arthroscopy portals and incisions for anterior cruciate ligament surgery: an anatomic study. Am Sports Med 2000; 28: 562-7.

Correspondence to: Ali Frrat Esmer, MD

Department of Anatomy,

School of Medicine, Ankara University

Sinhiye 06100 Ankara, Turkey

Phone: +90 31231050 01; Fax: +90 3123105001

e-mail: alife76@yahoo.com

Conflict of interest statement: No conflicts declared. 